\title{
STRAIN ANALYSIS IN NARROW BOREHOLES BY MEANS OF MICROSCOPIC DIGITAL IMAGE CORRELATION
}

\author{
Edgar PERETZKI ${ }^{1}$, Thomas LEHMANN ${ }^{1}$, Martin STOCKMANN ${ }^{1}$, Jörn IHLEMANN ${ }^{1}$ \\ 1 Chemnitz University of Technology, Chair of Solid Mechanics, Reichenhainer Str. 70, \\ 09126 Chemnitz, Germany, E-mail: edgar.peretzki@mb.tu-chemnitz.de
}

\section{Introduction}

The Digital Image Correlation (DIC) is a frequently used method for the analysis of displacement and strain fields in experimental mechanics. It is widely used due to its versatility. Thus, analyses can be performed on very large down to microscopically small objects $[1,2]$. This abstract describes, how the displacement field at the bottom of a narrow borehole can be investigated using DIC. In the following section, the investigated specimen is described, as well as the application of the speckle pattern required for the DIC.

\section{Specimen and speckle pattern application}

For the investigations a test specimen was designed and manufactured from polycarbonate, see Fig. 1. The borehole has a diameter of $6 \mathrm{~mm}$ and a depth of $8 \mathrm{~mm}$ with a plain bottom.

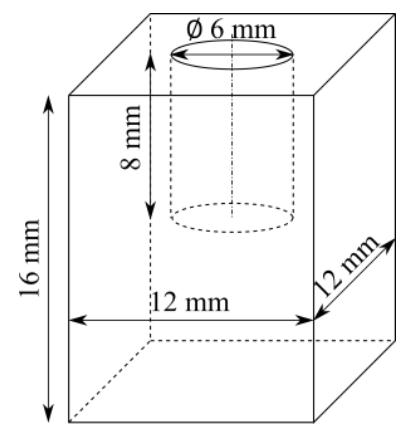

Fig. 1. Test specimen with borehole.

The DIC requires a randomly distributed speckle pattern. Its manufacture and application are described below. The structure of the speckle pattern is directly related to the size of the object field. The smaller the field, the finer the speckle pattern has to be, so that a high resolution can be achieved. The production of such a pattern was already described in [3], but slightly modified. Instead of a direct application on the measuring object, a thin foil was first produced, which was then applied to the test specimen using adhesive, see Fig. 2.
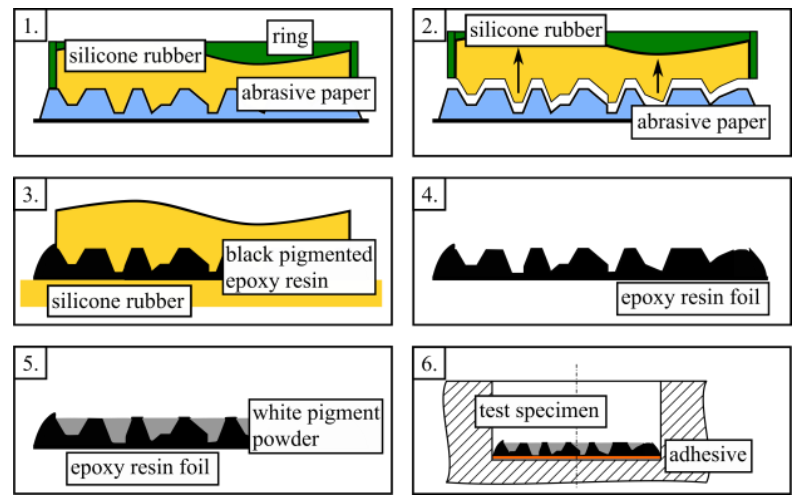

Fig. 2. Manufacturing of the speckle pattern.

The first step of the preparation was to cast liquid silicone rubber on the surface of an abrasive paper with the grain size 1000. After curing, the rubber could be separated with the negative of the abrasive paper. In the third step a drop of black pigmented epoxy resin was applied to a plane silicone rubber surface and covered with the abrasive paper negative. A thin epoxy foil was separated after curing that contains a rough surface. The hollows were coloured with white pigments. In the last step, a suitably cut foil was adhered to the hole bottom of the specimen using epoxy resin or cyanoacrylate.

\section{Experimental setup}

In the previous section, the preparation of the specimen was described. For future investigations, it is necessary to have a $2 \mathrm{~mm}$ diameter hole in the bottom of the $6 \mathrm{~mm}$ diameter borehole, see Fig. 3 .
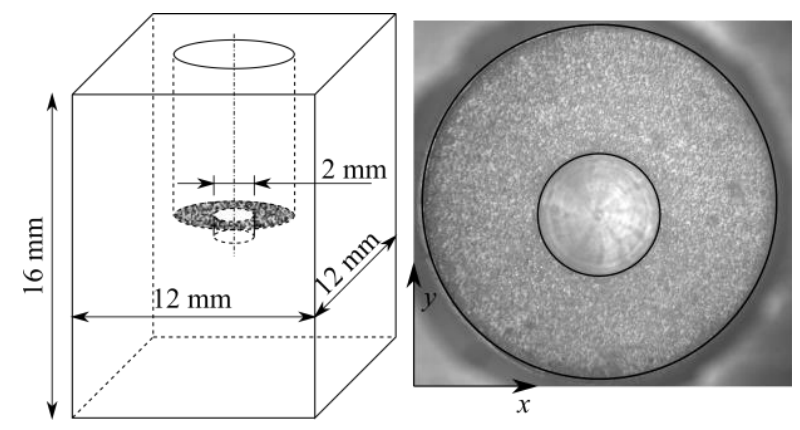

Fig. 3. Test specimen and speckle pattern at the bottom. 
In Fig. 3 the test specimen and the view into the borehole containing the speckle pattern is shown. The test specimen was integrated into the experimental setup, as depicted schematically in Fig. 4.

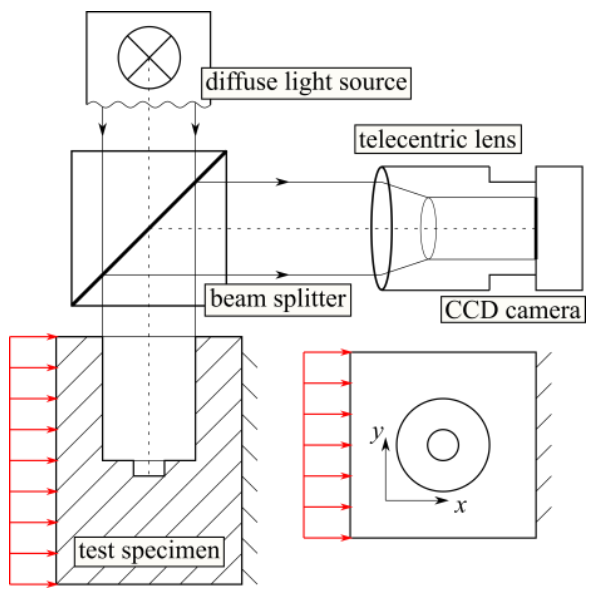

Fig. 4. Experimental Setup.

Illuminating of the borehole bottom is essential to achieve the image quality, which is required for the DIC. A beam splitter enables the illumination with simultaneous image acquisition. The images were taken by a CCD camera with a telecentric lens. Fixed in a loading device, the specimen was set under compressive forces that were monitored with a load cell $(10 \mathrm{kN})$ in several load steps. With each load step, the compressive force was increased by $200 \mathrm{~N}$ and an image was captured. These images are the basis of the evaluation, which is described in the next section.

\section{Analysis and Results}

The used CCD camera has a resolution of $1280 \times 980$ pixel. The selection of the telecentric lens results in an object field of $8.8 \mathrm{~mm} \times 6.6 \mathrm{~mm}$, that allows optimal observation of the prepared annulus at the bottom of the hole.

For the evaluation, the program GOM Correlate Professional 2018 was used first. The captured images were imported into this program. The software creates facets and tracks them during the load steps. For further processing of the data in Matlab, the coordinates of the facets were exported. The displacement and strain fields were calculated from the exported data. A parametrisation was used which is based on calculations in [4] that was adapted to the annulus around the small borehole. Fig. 5 shows the measured displacement field and the calculated strain field of the annulus at a load of $1000 \mathrm{~N}$. A superposition of rigid body displacement and deformation occurs. The further away the coordinates are from the clamping, the greater the displacement.

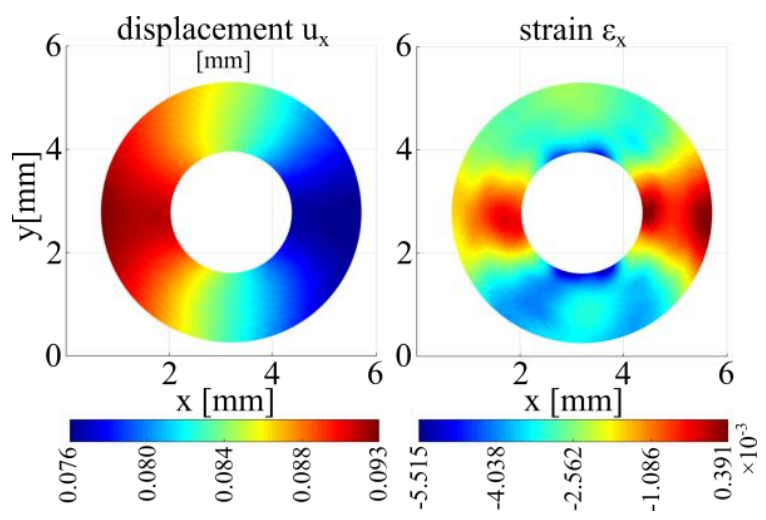

Fig. 5. Displacement and strain field of the annulus at a force of $1000 \mathrm{~N}$.

The resulted strain is almost symmetrical to the horizontal in the middle of the borehole, which corresponds to the expectations.

\section{Conclusions}

The speckle patterns based on abrasive paper could be applied in a narrow borehole. By the described measuring strategy, it was possible to take pictures of the borehole bottom, from which displacement and strain fields could be determined by DIC and a parameterised evaluation.

\section{Acknowledgements}

This work is part of a measure which is cofinanced by means of taxation on the basis of that of the deputies of the Saxon Parliament (Landtag) decided budget. The financial support is gratefully acknowledged.

\section{References}

[1] Rastogi P. K., Photomechanics. Springer Berlin Heidelberg, 2000.

[2] Sutton, M. A., Orteu, J., Schreier, H., Image correlation for shape, motion and deformation measurements. Springer Science+Business Media, 2009.

[3] Peretzki, E., Stockmann, M., Lehmann, T., Ihlemann, J. A new surface preparation method for microscopic digital image correlation applications. In Extended abstracts of the $35^{\text {th }}$ Danubia Adria Symposium, Sinaia, 25-28 Sep, 2018, 81-82

[4] Lehmann, T., Stockmann, M., Ihlemann, J. A method for strain analyses of surfaces with curved boundaries based on measured displacement fields. In Extended abstracts of the $35^{\text {th }}$ Danubia Adria Symposium, Sinaia, 25-28 Sep, 2018, 13-14 